\title{
Vitamin D Deficiency among Females with Acne Vulgaris in Relation to Sun Exposure: A Cross-sectional Study
}

\author{
Ghada Abdelrahman Elfadil $^{1 *}$, Nosiba Ahmed Mohammed ${ }^{2}$, Abdelgadir Elmugadam $^{1}$, Marwan Ismail $^{3}$, Abd Elgadir Alamin Altoum $^{3}$ \\ Ahmed L Osman ${ }^{3}$ \\ ${ }^{1}$ Department of Clinical Chemistry, College of Medical Laboratory Science, Sudan University of Science and Technology, Khartoum, \\ Sudan; ${ }^{2}$ Department of Clinical Chemistry, College of Medical Laboratory Science, Sudan University of Science and Technology- \\ Khartoum - Sudan; ${ }^{3}$ Department of Medical Laboratory Sciences, College of Health Sciences, Gulf Medical University, Ajman, UAE
}

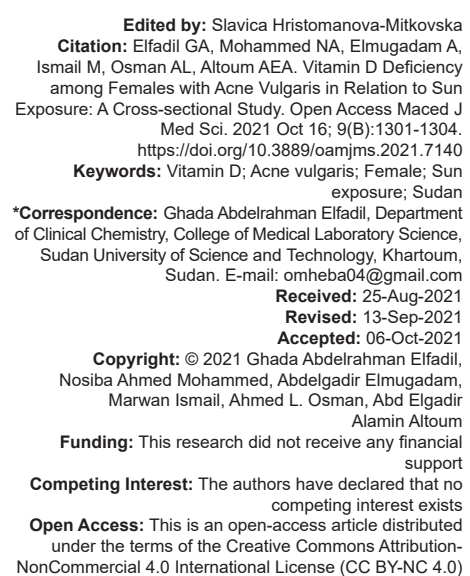

Edited by: Slavica Hristomanova-Mitkovska Edited by: Slavica Hristomanova-Mitkovska
Citation: Elfadil GA, Mohammed NA, Elmugadam A, Citation: Elfadil GA, Mohammed NA, Elmugadam A,
smail M, Osman AL, Altoum AEA. Vitamin D Deficiency Ismail M, Osman AL, Altoum AEA. Vitamin D Deficiency
among Females with Acne Vulgaris in Relation to Sun Exposure: A Cross-sectional Study. Open Access Maced J Med Sci. 2021 Oct 16; 9(B): 1301-1304
Med https://doi.org/10.3889/oamjms.2021.7140
. Keywords: Vitamin D; Acne vulgaris; Female; Sun *Correspondence: Ghada Abdelrahman Elfadil, Department of Clinical Chemistry, College of Medical Laboratory Science, Sudan University of Science and Technology, Khartoum Sudan. E-mail: omheba04@gmail.com Revised: $13-$-Sep-2021 Accepted: $06-\mathrm{S}-\mathrm{Oct}-2021$ Accepted: 06-Oct-2021
Copyright: $\odot 2021$ Ghada Abdelrahman Elfadil, Nosiba Ahmed Mohammed, Abdelgadir Elmugadam, Marwan Ismail, Ahmed L. Osman, Abd Elgadir Alamin Altoum

Funding: This research did not receive any financial Competing Interest: The authors have declared that no Open Access: This is an open-access articterest exists under the terms of the Creative Commons Attributionunder the terms of the Creative Commons Attribution-

\begin{abstract}
BACKGROUND: Acne vulgaris is a common chronic inflammatory disease of the skin. Vitamin D deficiency has been implicated in various skin diseases, including atopic dermatitis and psoriasis.

AIM: The aim of this study was to evaluate the serum 25-hydroxy Vitamin D levels among patients with acne vulgaris. METHODS: This was a cross-sectional comparative study performed in Khartoum state at Military hospital department of dermatology and venerology, 111 blood samples were collected from females to measure serum level of 25-hydroxy Vitamin D by immunoassay analyzer cobas-e-411-2ed generation platform of Electrochemiluminescence binding assay.

RESULTS: In this study, 111 females their age 18-36 years. 57 suffering from acne vulgaris, $61.4 \%$ of them had moderate grade of acne. A significant decrease in the serum 25-hydroxy Vitamin D concentrations in acne vulgaris patients when compared to 54 non-acne group $(13.3 \pm 5.0 \mathrm{ng} / \mathrm{mL}$ vs. $24.2 \pm 10.3 \mathrm{ng} / \mathrm{mL} p=0.00)$. Significant positive correlation between serum 25-OH Vitamin $D$ and exposure to sunlight per day $(r=0.562, p=0.00)$, while there was a significant negative correlation between $25-\mathrm{OH}$ Vitamin $\mathrm{D}$ and grade of acne, and duration of disease per month (for grade of acne $r=-0.641, p=0.00$ ), (for duration of disease $r=-0.696, p=0.00$ ) among patients with acne vulgaris CONCLUSION: The evidence from this study suggests that female with low serum 25- OH Vitamin D had increase risk to develop acne vulgaris. Further studies are needed to confirm this potential relation.
\end{abstract}

\section{Introduction}

Acne is the most common skin disease of adolescentsandyoungadults[1]. Itisacomplexskindisorder that distresses many patients because of its chronicity. Although multiple factors contribute to acne development, chronic inflammation is an important mechanism. Several inflammatory mediators such as cytokines and neuropeptides have been identified in acne lesions [2].

There are many factors which regulate sebaceous glands function including androgen stimulation, Vitamin D, and insulin-like growth factor one. Sebaceous follicles that have micro-comedones provide an anerobic and lipid-rich environment which is ideal for Propionibacterium acnes activity [3]. $P$ acnes trigger cytokine activation by toll-like receptors, indicating the role of innate immunity in acne development [4]. This immune-mediated inflammation may involve CD4+ lymphocytes and macrophages which stimulates the pilosebaceous vasculature and precede follicular hyperkeratinization [5].

Vitamin $D$ has a number of functions. It is associated with systemic inflammatory diseases such as rheumatoid arthritis, systemic lupus erythematosus, and inflammatory bowel disease [6], [7]. In dermatological diseases, Vitamin D plays an important role as an immune modulator in atopic dermatitis, psoriasis, and alopecia [8], [9]. Vitamin D regulates the immune system and the proliferation and differentiation of keratinocytes and sebocytes. Moreover, it has anticomedogenic and antioxidant effect. Hence, a Vitamin $D$ deficiency may facilitate the pathogenesis of acne [10]. In vitro studies identified Vitamin D receptors in human sebocytes [11]. Vitamin D has been found to modulate lipid and cytokine production which suggest its possible role in acne pathophysiology [12].

This study aimed to assess serum levels of 25-hydroxy Vitamin D in patients with acne vulgaris and its relation to sunlight exposure and duration of disease. 


\section{Methods}

\section{Study design}

This is a cross-sectional and descriptive study.

\section{Study setting and period}

The research was carried out in the Department of Dermatology and Venerology at Military Hospital in Khartoum State (hospital for referring to it from all States of Sudan) during period October 2019-March 2020.

\section{Selection criteria}

Sudanese female clinically diagnosed with different grade of acne according to the global acne grading system [13]. The selection was done by dermatology consultant. Femaleontreatmentwith VitaminD supplement, presence of known systemic diseases, dermatological diseases other variants than acne, pregnant, lactating women, hematological and endocrine disorders and also, patients receiving drugs such as diuretics, multivitamins, anticonvulsants, glucocorticoids, erythromycin, and estrogen compound pills were excluded from the study.

\section{Ethical clearance}

The study was approved by the internal review research board at Sudan University of Science and Technology. The objectives of the study were explained to all individuals participating in this study. Verbal consent was obtained from all participants in the study.

\section{Sampling}

After getting their consent, venous blood samples were taken from participants in the morning after a minimum of $8 \mathrm{~h}$ of overnight fasting. Then, specimens were centrifuged at $3000 \mathrm{rpm}$ for $5 \mathrm{~min}$; serum was separated and stored at $-20^{\circ} \mathrm{C}$.

\section{Body mass index (BMI)}

Height and weight were taken using standard protocols. BMI was calculated as weight (in kilograms) divided by height (in meters squared). All measurements were performed twice by the well experience nurse in clinic.

\section{Measurement of Vitamin D}

Serum 25-OH Vitamin D level was measured using the competitive inhibition enzyme-linked immunosorbent assay (cobas-e-411-2ed generation platform of Electrochemiluminescence binding assay). According to manufacturer's protocol, $200 \mu \mathrm{l}$ sample was added into biotin-coated monoclonal anti-Vit-D antibodies, followed by competitive binding of $100 \mu \mathrm{l}$ Vit-D-labeled [14].

\section{Statistical analysis}

The Statistical Package for the Social Sciences (SPSS) version 16.0 (SPSS Inc., Chicago, USA) was used for the data analysis. Data were presented as frequencies, percentage, and means \pm standard deviation. The Student's t-test was used to compare mean levels of study parameters between groups. Categorical variables were compared using Chi-square and multiple regression tests. Pearson's correlation coefficient test was employed to evaluate the relationship between continuous variables. $p \leq 0.05$ was used as the statistical significance.

\section{Results}

A Total of 111 females were recruited; their age between 18-36 years. 57 female (51.3\%) had ance vulgaris, 54 females $(48.7 \%)$ had no acne. According to grade of acne, $35(61.4 \%)$ of them had moderate grade of acne as in Table 1.

Table 1: Demographic and characteristics of study group

\begin{tabular}{ll}
\hline Characteristic & Frequency \\
\hline Age & \\
$18-25$ years & $86(78.0 \%)$ \\
$26-36$ years & $24(22.0 \%)$ \\
BMl & \\
$\quad$ Normal weight & $103(92.8 \%)$ \\
$\quad$ Overweight & $08(7.2 \%)$ \\
Acne vulgaris & \\
$\quad$ Yes & $57(51.3 \%)$ \\
No & $54(48.7 \%)$ \\
Grade of acne & \\
$\quad$ Mild & $11(19.3 \%)$ \\
Moderate & $35(61.4 \%)$ \\
Sever & $11(19.3 \%)$ \\
Use of sun blocker & \\
Yes & $23(21.0 \%)$ \\
$\quad$ No & $88(79.0 \%)$ \\
Family history of acne vulgaris & \\
Yes & $9(8.0 \%)$ \\
No & $102(92.0 \%)$ \\
Exposure to sunlight per day & \\
1-2 $\mathrm{h}$ & $35(31.5 \%)$ \\
$3-5 \mathrm{~h}$ & $67(68.5 \%)$ \\
\hline
\end{tabular}

The mean values of Vitamin $D$ were significantly lower among female with acne when compared with non-acne female $(p<0.01)$. However, the mean values of BMI were significantly higher in females with acne

Table 2: Comparison between means of age (years), BMI $\left(\mathrm{kg} / \mathrm{m}^{2}\right)$, and Vitamin D levels in study group

\begin{tabular}{llc}
\hline Variable & Mean \pm SD & p value \\
\hline Age/years & $22.5 \pm 3.8$ & \\
$\quad$ Acne patient & $23.7 \pm 3.9$ & 0.153 \\
$\quad$ Non-Acne & $22.6 \pm 2.7$ & \\
BMI Kg/m & & $0.036^{*}$ \\
$\quad$ Acne patient & $21.7 \pm 1.8$ & \\
$\quad$ Non-Acne & $13.3 \pm 5.0$ & $0.00^{*}$ \\
Vitamin D ng/mL & $24.2 \pm 10.3$ & \\
$\quad$ Acne patient & & \\
Non-Acne & &
\end{tabular}


when compared with non-acne female $(p=0.036)$ as in Table 2. The frequency Vitamin $\mathrm{D} \mathrm{ng} / \mathrm{mL}$ among study group according to reference range, subjects were divided into 3 categories: Severe Vitamin D deficiency $[25(\mathrm{OH}) \mathrm{D}<10 \mathrm{ng} / \mathrm{ml}]$, the frequency of nonacne disease was (1.8\%) compare to Acne Patients $(13.5 \%)$ which is more, Vitamin D deficiency $[25(\mathrm{OH})$ D 10-<20 ng/ ml], the frequency of non-acne disease was $(16.2 \%)$ compare to acne patients $(30.6 \%)$ which is more, and insufficiency [25(OH)D 20-<30 ng/ml] ], the frequency of non-acne disease was (20.7\%) compare to acne patients $(7.2 \%)$ which is less as in Table 3.

Table 3: Frequency of 25-OH Vitamin D among study group according to reference range.

\begin{tabular}{lll}
\hline Vitamin D: ng/mL & Frequency $(\%)$ & \\
\cline { 2 - 3 } & Non-Acne disease & Acne patients \\
\hline$<10$ & 02 & 15 \\
Severe Vitamin D deficiency & $(1.8 \%)$ & $(13.5 \%)$ \\
$10-19$ & 18 & 34 \\
Vitamin D deficiency & $(16.2 \%)$ & $(30.6 \%)$ \\
$20-29$ & 23 & 8 \\
Vitamin D insufficient & $(20.7 \%)$ & $(7.2 \%)$ \\
$30-49$ & 10 & 0 \\
Vitamin D optimal & $(9.0 \%)$ & $(0 \%)$ \\
$50-69$ & 1 & 0 \\
Upper normal & $(0.9 \%)$ & $(0 \%)$ \\
$70-150$ & 0 & 0 \\
Overdose Vitamin D not toxic & $(0 \%)$ & $(0 \%)$ \\
$>150$ & 0 & 0 \\
Vitamin D intoxication & $(0 \%)$ & $(0 \%)$ \\
\hline
\end{tabular}

The results of the study revealed that acne vulgaris disease was significantly associated with Vitamin D deficient, number of hours exposure to sunlight per days $(p<0.01)$. Furthermore, they increased the risk of acne disease with Vitamin $D$ deficient - odd ratio (OR): 1.256 with confidence interval $(\mathrm{Cl})$ : (1.097-1.437) and sun exposure - OR: 3.438 with $\mathrm{Cl}$ : (1.450-8.150), $\mathrm{p}<0.01$ as in Table 4.

Table 4: Study variables and parameters classified according to the presence of Acne vulgaris

\begin{tabular}{|c|c|c|c|c|}
\hline \multirow{2}{*}{$\begin{array}{l}\text { Variables and } \\
\text { parameters }\end{array}$} & \multicolumn{2}{|l|}{ Frequency (\%) } & \multirow[t]{2}{*}{$\mathrm{OR}(\mathrm{Cl})$} & \multirow[t]{2}{*}{ P-value } \\
\hline & Non-Acne disease & Acne patients & & \\
\hline \multicolumn{5}{|l|}{ Vit D: ng/mL } \\
\hline$<30$ & $43(38.7 \%)$ & 57 (51.4\%) & 1.256 & 0.00 \\
\hline$\geq 30$ & $11(9.9 \%)$ & $0(0.0 \%)$ & $(1.097-1.437)$ & \\
\hline \multicolumn{5}{|c|}{ Exposure to sunlight } \\
\hline 1-2 h/day & $10(09.0 \%)$ & $25(22.5 \%)$ & 3.438 & 0.005 \\
\hline $3-5$ h/day & $44(39.6 \%)$ & $32(28.8 \%)$ & $(1.450-8.150)$ & \\
\hline
\end{tabular}

The relationship between Vitamin $D$ and other studied variables and parameters was determined. A significant positive correlation was found between Vitamin $D$ and exposure to sunlight $(r=0.562 ; p<0.01)$. In addition, Vitamin $D$ was negatively correlated with the grade of acne $(r=-0.641 ; p<0.01)$, duration of disease $(R=-0.696 ; p<0.01)$. The results were presented in Table 5.

Table 5: Correlation between serum 25-OH Vitamin D and exposure to sunlight per day, grate of acne, and duration of disease among patients with Acne vulgaris

\begin{tabular}{lll}
\hline Variables & $25-\mathrm{OH}$ Vitamin D & $\mathrm{p}$ \\
\cline { 2 - 2 } & $\mathrm{R}$ & \\
\hline Exposure to sunlight per day & 0.562 & 0.000 \\
Grate of Acne vulgaris & -0.641 & 0.000 \\
Duration of disease/month & -0.696 & 0.000 \\
\hline
\end{tabular}

\section{Discussion}

Acne vulgaris is a multifactorial chronic inflammatory disorder of the pilosebaceous follicles of human skin [3]. Recent studies in Sudan revealed a higher percentage of Vitamin $D$ deficiency among women in Sudan [15]; this may be attributed to nutritional, skin color, sun exposure times, and uses of sun blockers.

In this study, there were significant low serum levels of 25-hydroxy Vitamin D in acne vulgaris female when compared to non-acne female. Serum level of 25-hydroxy Vitamin D was found to be inversely related to acne severity, suggesting that there is a connection between low Vitamin $\mathrm{D}$ and acne. This is in agreement with a previous study which found a decrease in the levels of 25-hydroxy Vitamin D in patients with nodulocystic acne than that in the control group [16]. Furthermore, Lim et al. found a significant lower Vitamin D level in patients with acne than normal subjects [17]. Vitamin D levels were inversely correlated with acne severity, especially in patients with more inflammatory lesions. Vitamin D regulates the immune system and the proliferation and differentiation of keratinocytes and sebocytes. Moreover, it has antioxidant and anticomedogenic properties. Hence, a Vitamin D deficiency may contribute in the pathogenesis of acne vulgaris [3], [10], [18]. This study found that the increase exposure to sunlight per day was significantly positive correlated with Vitamin $\mathrm{D}$ level, by increasing skin exposure to sunlight [18], increasing lipolysis, and enhancing mobilization of deposited Vitamin $D$ from the fat compartments [19].

\section{Conclusion}

The data of the present study revealed that Sudanese female Vitamin $D<30 \mathrm{ng} / \mathrm{ml}$ had high risk to develop acne. Moreover, Vitamin D level was inversely associated with the grade and duration of disease, while it is proportionally associated with exposure to sunlight. Therefore, monitoring and supplementation regimens of Vitamin $D$ are recommended.

\section{What is already known on this topic}

Vitamin D has been found to modulate lipid and cytokine production which suggests its possible role in acne pathophysiology. 


\section{What this study adds}

The evidence from this study suggests that female with low serum 25- OH Vitamin D had increase risk to develop acne vulgaris

\section{Authors' contributions}

GAE and NAM conceived and designed the study; GAE, AAA, and AE implemented the study; GAE and AE supervised the study; GAE, MI, and NAM conducted data analysis; GAE, AE, AAA, MI, and NAM interpreted study results; GAE wrote the first draft of the manuscript; $A E E$ and $A E$ reviewed and corrected the draft manuscript. All the authors have read and agreed to the final manuscript.

\section{Acknowledgments}

Authors are grateful to the Military Hospital staff whom facilitated the diagnosis of patients and specimen collection.

\section{References}

1. Shen $Y$, Wang T, Zhou C, Wang X, Ding X, Tian S, et al. Prevalence of acne vulgaris in Chinese adolescents and adults: A communitybased study of 17,345 subjects in six cities. Acta Derm Venereol. 2012;92(1):40-4. http://doi.org/10.2340/00015555-1164 PMid:21710106

2. Tanghetti EA. The role of inflammation in the pathology of acne. J Clin Aesthet Dermatol. 2013;6(9):27-35. PMid:24062871

3. El-Hamd MA, El Taieb MA, Ibrahim HM, Aly SS. Vitamin D levels in acne vulgaris patients treated with oral isotretinoin. $\mathrm{J}$ Cosmet Dermatol. 2019;18(1):16-20. http://doi.org/10.1111/jocd.12503 PMid:29460332

4. Layton A, Anne EE, Zouboulis C. Acne. In: Griffiths C, Barker J, Bleiker T, Chalmers R, Creamer D, editors. Rook's Text Book of Dermatology. London, UK: John Wiley and Sons, Ltd.; 2016. p. 2343-407.

5. Jeremy $A H$, Holland DB, Roberts SG, Thomson KF, Cunliffe WJ. Inflammatory events are involved in acne lesion initiation. J Invest Dermatol. 2003;121(1):20-27. http://doi. org/10.1046/j.1523-1747.2003.12321.x PMid:12839559

6. Arnson $\mathrm{Y}$, Amital H, Shoenfeld Y. Vitamin D and autoimmunity: New aetiological and therapeutic considerations. Ann Rheum Dis.
2007;66(9):1137-42. http://doi.org/10.1136/ard.2007.069831 PMid: 17557889

7. Kostoglou-Athanassiou I, Athanassiou P, Lyraki A, Raftakis I, Antoniadis C. Vitamin D and rheumatoid arthritis. Ther Adv Endocrinol Metab. 2012;3(6):181-7.

PMid:23323190

8. Cheng HM, Kim S, Park GH, Chang SE, Bang S, Won CH, et al. Low vitamin $D$ levels are associated with atopic dermatitis, but not allergic rhinitis, asthma, or IgE sensitization, in the adult Korean population. J Allergy Clin Immunol. 2014;133(4):1048- 55. http:// doi.org/10.1016/j.jaci.2013.10.055 jPMid:24388009

9. Aksu Cerman A, Sarikaya Solak S, Kivanc Altunay I. Vitamin $\mathrm{D}$ deficiency in alopecia areata. $\mathrm{Br} \mathrm{J}$ Dermatol. 2014;170(6):1299- 304. http://doi.org/10.1111/bjd.12980 PMid:24655364

10. Lee WJ, Choi YH, Sohn MY, Lee SJ, Kim DW. Expression of inflammatory biomarkers from cultured sebocytes was influenced by treatment with Vitamin D. Indian J Dermatol. 2013;58(4):327-9. http://doi.org/10.4103/0019-5154.113959 PMid:23919024

11. Agak GW, Qin M, Nobe J, Kim MH, Krutzik SR, Tristan GR, et al Propionibacterium acnes induces an il-17 response in acne vulgaris that is regulated by Vitamin A and Vitamin D. J Invest Dermatol. 2014;134(2):366-73. http://doi.org/10.1038/ jid.2013.334 PMid:23924903

12. Steinman $L$. A brief history of $T(H) 17$, the first major revision in the $T(H) 1 / T(H) 2$ hypothesis of $T$ cell-mediated tissue damage. Nat Med. 2007;13(3):385. http://doi.org/10.1038/nm1551 PMid:17290272

13. Doshi A, Zaheer A, Stiller MJ. A comparison of current acne grading systems and proposal of a novel system. Int J Dermatol. 1997;36(6):416-8. http://doi. org/10.1046/j.1365-4362.1997.00099.x

PMid:9248884

14. Hathcock JN, Shao A, Vieth R, Heaney R. Risk assessment for Vitamin D. Am J Clin Nutr. 2007;85(1):6-18. http://doi. org/10.1093/ajcn/85.1.6 PMid:17209171

15. Husain NE, Suliman AA, Abdelrahman I, Bedri SA, Musa RM, Osman HE, et al. Vitamin D level and its determinants among Sudanese women: Does it matter in a sunshine African country? J Family Med Prim Care 2019;8(7):2389-94. http://doi. org/10.4103/jfmpc.jfmpc_247_19

PMid:31463263

16. Yildizgoren MT, Togral AK. Preliminary evidence for Vitamin D deficiency in nodulocystic acne. Dermatoendocrinol. 2014;6(1):e983687. http://doi.org/10.4161/derm.29799 PMid:26413187

17. Lim SK, Ha JM, Lee YH, Lee $\mathrm{Y}$, Seo YJ, Kim CD, et al Comparison of Vitamin $D$ levels in patients with and without acne: A case-control study combined with a randomized controlled trial. PLoS One. 2016;11(8):e0161162. http://doi. org/10.1371/journal.pone.0161162

PMid:27560161

18. vanEttenE, Mathieu C.Immunoregulation by 1,25-dihydroxyvitamin D3: Basic concepts. J Steroid Biochem Mol Biol. 2005;97(1-2):93- 101. http://doi.org/10.1016/j. jsbmb.2005.06.002 PMid: 16046118

19. Almehmadi B, Fallata E, Alqahtani S, Al-Agha A. The effects of physical activity and sun exposure on Vitamin $D$ status among children from Jeddah, Saudi Arabia. J Pediatr Care. 2016;2:1-4. 